\title{
Copper and very low birthweight babies
}

\author{
T L SOO, K SIMMER, L CARLSON, AND L MCDONALD
}

Department of Paediatrics and Gastrointestinal Laboratory, St Thomas's Hospital, London

SUMMARY Serum concentrations of copper and ceruloplasmin were measured in 24 very low birthweight babies. They were high in those weighing less than $1000 \mathrm{~g}$, and critically ill or receiving intravenous nutrition, and normal in those with bone disease, neutropenia, or oedema. Care is needed to maintain adequate concentrations without toxicity.

Copper is an essential trace element found in several metalloenzymes, including lysyl oxidase, cytochrome $\mathrm{C}$ oxidase, and superoxide dismutase. As the survival of infants born at less than 28 weeks' gestation has increased a new population is growing up that is at risk of copper deficiency because of low body stores and artificial feeding. The aim of this study was to measure serum copper and ceruloplasmin concentrations in very low birthweight (VLBW) babies to find out whether copper given intravenously is metabolised, and whether deficiency can be detected by the methods that we used.

\section{Patients and methods}

Twenty four VLBW babies were studied. Their mean gestational age was 28 weeks (range 24-35) and mean birthweight $1088 \mathrm{~g}$ (range 650-1460 g); 12 were boys and three were small for gestational age. Total parenteral nutrition was started on day 3 and fat emulsion (Intralipid, KabiVitrum) was introduced on day 5. Amino acids were given as Vamin. Small amounts of breast milk were given if tolerated. The total parenteral nutrition supplied $0.22 \mu \mathrm{mol} / \mathrm{kg}$ copper (Ped-El, KabiVitrum), $1.00 \mathrm{mmol} / \mathrm{kg}$ calcium, $1.16 \mathrm{mmol} / \mathrm{kg}$ phosphate and $200 \mathrm{U}$ vitamin $\mathrm{D}$ daily. When the babies were having enteral feeds, multivitamins (including $800 \mathrm{U}$ vitamin D) were prescribed from 2 weeks of age, with an additional $1000 \mathrm{U}$ of vitamin $\mathrm{D}$ for those whose birthweight had been less than $1000 \mathrm{~g}$. Breast fed babies weighing $<1200 \mathrm{~g}$ were given a neutral sodium phosphate supplement $(1 \mathrm{mmol} / \mathrm{kg} /$ day $)$. The calculated intakes of copper in babies receiving full enteral feeds were 0.63-1.23 $\mu \mathrm{mol}$ and $1.13-1.5 \mu \mathrm{mol} / \mathrm{kg} / \mathrm{day}$ on breast milk and formulae feed, respectively. One baby received maintenance treatment with frusemide for chronic lung disease.
Albumin low in salt was infused in all babies with serum albumin concentrations of less than $20 \mathrm{~g} / 1$.

A sample of $0.2 \mathrm{ml}$ serum was diluted in $0.8 \mathrm{ml}$ molar hydrochloric acid for copper analysis by atomic absorption spectrophotometry (Instrumentation Laboratories AA/AE 257). Standards ranged from 1-17 $\mu \mathrm{mol} / \mathrm{l}$. All glassware and test tubes were soaked in $\mathbf{0 . 1} \mathrm{M}$ hydrochloric acid for a minimum of one day and rinsed three times in deionised water. A sample of $0.1 \mathrm{ml}$ serum was frozen for ceruloplasmin analysis by immunoradial diffusion. Babies who had been transferred to another hospital or home did not have all the samples taken. $X$ ray pictures of the babies knees were taken and determinations of plasma alkaline phosphatase activity and phosphorus concentration were made as a routine. The $x$-ray pictures were reviewed by a radiologist (LMcD) who had no clinical information about the babies, and bone disease of prematurity was diagnosed if there were signs of osteopenia and metaphyseal changes.

All results are given as mean (SEM) and analysed using Student's unpaired $t$ test and least squares linear regression.

\section{Results}

There was no correlation between gestational age and serum copper concentration at 1 week $(r=0.01)$. Babies with birth weights of less than $1000 \mathrm{~g}$ had higher serum copper concentrations at 1 week than those with birth weights of 1000-1500 g: $13 \cdot 1$ (1.9) $\mu \mathrm{mol}(\mathrm{n}=7)$ and $8.9(0 \cdot 8) \mu \mathrm{mol} / \mathrm{l}(\mathrm{n}=12)(\mathrm{p}<0.05)$. There was no significant change with postnatal age, the mean serum copper concentration at 1 month being $10.7(0.7) \mu \mathrm{mol} / \mathrm{l}$.

As the concentrations did not change with postnatal age concentrations at 1 week and 1 month were combined and the effect of feeding determined. Babies receiving parenteral feeds had significantly higher serum copper concentrations than babies receiving full enteral feeds $(p<0 \cdot 005)$.

Serum concentrations of ceruloplasmin correlated with those of serum copper $(r=0.89, p<0 \cdot 001)$. The mean ceruloplasmin:copper ratio was 0.19 (range 0.08-0.24). Four babies had high serum copper concentrations $(18 \cdot 8-20.9 \mu \mathrm{mol} / \mathrm{l})$; all were receiving total parenteral nutrition and critically ill (with necrotising enterocolitis, septicaemia, and intracra- 


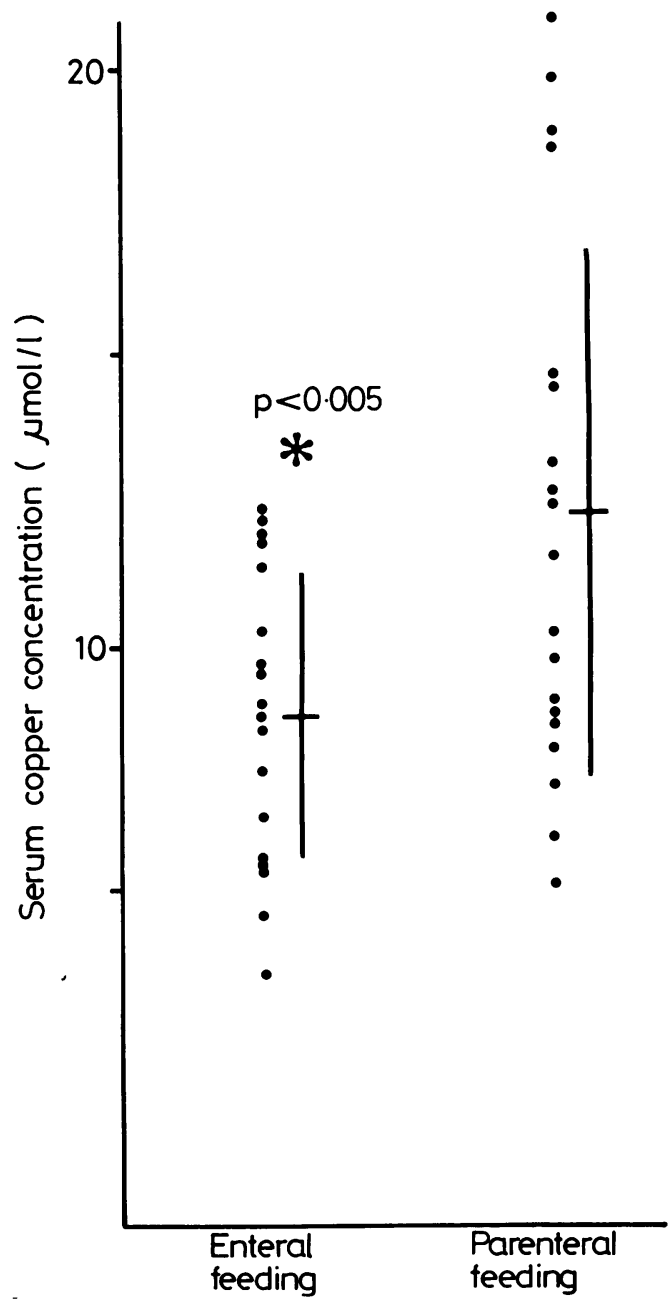

Figure Mean (SD) serum copper concentrations in very low birthweight babies fed enterally and parenterally.

nial haemorrhage) and their ceruloplasmin:copper ratios were $0 \cdot 13-0 \cdot 23$.

There was no difference in the serum copper concentrations at 1 month between those babies with and without bone disease, mean concentrations being $11.4(1.3) \mu \mathrm{mol} / \mathrm{l}(\mathrm{n}=9)$ and $10 \cdot 1(1.5) \mu \mathrm{mol} / \mathrm{l}$ $(n=9)$ respectively. As expected, the mean maximal alkaline phosphatase activities were higher in those infants with metabolic bone disease $487.9(55.3)$ $(n=9)$ compared with $297.5(33.6)$ IU/l $(n=6)$ $(p<0.05)$; there was no correlation between alkaline phosphatase activity and copper concentration. The mean minimal serum phosphorus concentrations in those infants with and without bone disease were
$1.36(0.02)$ and $1.55(0.57) \mathrm{mmol} / \mathrm{l}$, respectively. Five babies were neutropenic $\left(<1 \times 10^{9} / 1\right)$ and septic, and their mean copper concentration at 1 month was $12.5(2 \cdot 3) \mu \mathrm{mol} / \mathrm{l}$. There was no association between low serum copper concentrations and oedema. Seven babies required albumin infusions; their mean copper concentration was $11.8(4.9) \mu \mathrm{mol} / \mathrm{l}$ and in all the oedema resolved after the infusion.

\section{Discussion}

Serum copper concentrations at 1 week did not correlate with gestational age, and there was no significant change with postnatal age. Babies with birth weights of $<1000 \mathrm{~g}$ had significantly higher copper concentrations than those with birth weights of $>1000 \mathrm{~g}$, which probably reflects the frequent use of total parenteral nutrition in these babies as babies receiving total parenteral nutrition had higher mean serum copper concentrations. This could have been due to injury to the hepatobiliary system, as copper is excreted in the bile. Stress and infection are other possible causes, as are frequent blood transfusions.

As $93 \%$ of intravascular copper is bound to ceruloplasmin, possibly more important than a high serum copper concentration is the effect of any factor that might reduce the ceruloplasmin:copper ratio, thus increasing the diffusable copper fraction. Only one of our 24 VLBW babies had a reduced ceruloplasmin:copper ratio.

Copper deficiency reflected in apnoea, bone disease, oedema, anaemia, and neutropenia has previously been described in preterm infants between 8 weeks and 6 months of age. ${ }^{123}$ We found no evidence of it in our small sample studied at 3 months; there was a high incidence of subclinical metabolic bone disease but no evidence that this was due to copper deficiency. Recently, Sutton et al described four preterm infants who developed clinical copper deficiency with low plasma copper concentrations $;^{4}$ they were receiving formula containing $0.61 \mu \mathrm{mol} / \mathrm{l}$ whereas our formula, like most commercial formulas, contained $0 \cdot 80 \mu \mathrm{mol} / \mathrm{l}$ copper. The copper concentration of breast milk is lower, but the copper is more bioavailable.

In conclusion, parenteral nutrition containing $0.2 \mu \mathrm{mol} / \mathrm{kg} /$ day and infant formulas with a copper concentration of $0.80 \mu \mathrm{mol} / 100 \mathrm{ml}$ provide enough copper to maintain serum copper concentrations and prevent the clinical signs of copper deficiency. Serum copper reflects only a small fraction of total body copper, however, and is probably a poor reflection of the amount in the body. Measurement of enzymes dependent on copper (such as superoxide dismutase) may be more helpful. 
Current recommended doses range from $0 \cdot 10$ $1.48 \mu \mathrm{mol} / \mathrm{kg} /$ day, ${ }^{45}$ and some recommend that copper be excluded completely from short term parenteral nutrition. ${ }^{6}$ Our experience suggests that potentially toxic concentrations of copper can be achieved in critically ill preterm infants and that intravenous copper supplements should be withheld until the babies are stable, and then their serum copper concentrations should be monitored. Further studies are needed to define optimal intravenous copper requirements.

We are grateful to Dr RPH Thompson, Dr B Slavin, and Professor JW Scopes for their support.

\footnotetext{
References

1 Al-Rashid AA, Spangler J. Neonatal copper deficiency. N Engl J Med 1971;285:841-3.
}

${ }^{2}$ Askenazi A, Lewis S, Djaldetti M, Fishel M, Benvenish D. The syndrome of neonatal copper deficiency. Pediatrics 1973;52:525-32.

${ }^{3}$ Heller RM, Kirchner SG, O'Neill JA, et al. Skeletal changes of copper deficiency in infants receiving prolonged total, parenteral nutrition. J Pediatr 1978;92:947-59.

${ }^{4}$ Sutton AM, Harvie A, Cockburn F, Farquharson J, Logan RW. Copper deficiency in the preterm infant of very low birthweight. Arch Dis Child 1985;60:644-51.

5 James BE, Hendry PG, MacMahon RA. Total parenteral nutrition of premature infants. 2. Requirements for micronutrient elements. Aust $J$ Paediatr 1979;15:67-71.

6 Casey CB, Hambidge KM. Trace minerals. In: Tsang RC, ed. Vitamin and mineral requirements in preterm infants. New York: Marcel Dekker, 1985;153-84.

Correspondence to Dr Karen Simmer, Department of Paediatrics, Flinders Medical Centre, Bedford Park, South Australia 5042.

Received 13 July 1987

\title{
Maternal narcotic abuse and the newborn
}

\author{
L G ALROOMI, ${ }^{*} \mathrm{~J}$ DAVIDSON, $\dagger \mathrm{T} \mathrm{J}$ EVANS, $\uparrow$ P GALEA, ${ }^{*}$ AND R HOWAT* \\ ${ }^{*}$ Glasgow Royal Maternity Hospital and †Stobhill General Hospital, Glasgow
}

SUMmary In 50 infants born to women who continued to take heroin during all or part of their pregnancy the drug withdrawal symptoms were mild and were noted in 21 infants $(42 \%)$. Only nine infants required treatment. Sudden infant death syndrome occurred in two infants at 4 and 6 months.

An increasing number of infants are being born to mothers addicted to narcotic drugs. Reports about the effects of maternal drug abuse on the infant are conflicting. Previous series, largely from North America, have reported increased neonatal mortality and morbidity in these infants. ${ }^{12}$ Recently, Klenka reported minor withdrawal symptoms in more than $70 \%$ of infants but noted a low incidence of severe symptoms. ${ }^{3}$ This was attributed to smoking heroin rather than to intravenous abuse. In order to ascertain the current risk we studied 50 infants born between 1983 and 1986.

\section{Patients and methods}

During the study period, 44 women known to be addicted to narcotic drugs delivered 50 infants in two Glasgow maternity hospitals. One mother had a twin pregnancy, and five women delivered twice during this period. The combined annual delivery rate in these two hospitals is roughly 6000 .

All except one of the mothers were using heroin, either alone or in combination with a variety of other drugs. The one exception was a methadone addict. The mean (SD) duration of addiction before delivery was $2.7(1.5)$ years. The amount of heroin used varied widely and was difficult to ascertain. Most of the women (75\%) were intravenous heroin abusers; the rest either smoked or snorted the drug. Twenty four women had partners who were also drug addicts.

The ages of the mothers ranged from 17-34 years: mean (SD) 21.5 (3.4). All were offered routine antenatal care with the addition of an inpatient detoxification programme. Nineteen of the women had little or no antenatal care, and two concealed their pregnancies.

The infants were admitted routinely to the special care nursery after delivery and were observed for signs of drug withdrawal for 48 hours. Symptomatic infants remained under close observation. Treatment was initiated if there were constant tremulous movements, convulsions, or a disturbed sleep or behavioural pattern such as restlessness or crying within one hour of a feed. The drugs used in treatment were phenobarbitone, chloral hydrate, and phenobarbitone either singly or in combination depending on the individual clinician. 